\title{
PESQUISA DE ANTICORPOS CONTRA Cysticercus bovis, POR TESTE ELISA EM BOVINOS DE ABATEDOURO
}

\author{
Vanete Thomaz-Soccol ${ }^{1}$, Valmir Kowaleski Souza ${ }^{2}$, Oscar Lago Pessoa ${ }^{3}$, \\ João Carlos Minozzo ${ }^{3}$, Maria Carmo Pessoa-Silva ${ }^{4}$, Rafaela P.M.G. Peixoto², \\ Juliana Ferreira Moura ${ }^{1}$ \\ 1 Universidade Federal do Paraná - vanetesoccol@gmail.com \\ 2 Pontifícia Universidade Católica do Paraná, Campus de Curitiba \\ 3 Secretária de Saúde do Estado do Paraná - SESA \\ ${ }^{4}$ Secretaria da Agricultura e do Abastecimento do Paraná - SEAB
}

RESUMO: Com o objetivo de padronizar e avaliar a campo um teste sorológico para diagnóstico de cisticercose em bovinos foram examinados 812 animais procedentes de 139 municípios do Estado do Paraná, a maioria bovinos azebuados, machos e fêmeas, de grupo etário variando de 18 meses a 60 meses. Os animais foram devidamente identificados e abatidos em frigorífico comercial na região metropolitana de Curitiba. Dos animais que apresentaram cistos durante a Inspeção post-mortem foi colhida amostra de sangue, as quais foram submetidas ao teste ELISA para pesquisa de anticorpos contra-Cysticercus bovis. O coeficiente de sensibilidade para o teste ELISA foi de $83,6 \%$ e 0 Coeficiente de Especificidade foi de 92,8\%. Portanto, o teste sorológico (ELISA) foi mais sensível do que o exame póst-mortem, pois este deixou de detectar 06 carcaças com infecção leve por cisticercose (VPP 99,7\% - ELISA).

Palavras-chave: cisticercose; imunodiagnóstico; inspeção; rastrabilidade

\section{RESEARCH OF Cysticercus bovis ANTIBODIES BY ELISA TEST IN SLAUGHTERHOUSE ANIMALS}

\begin{abstract}
In order to standardize a serological test for diagnosing cysticercosis in cattle, 812 animals have been tested, most of them halfblooded zebu cattle, males and females, from age groups ranging from 18 months to 60 months. The animals had come from 139 municipalities in the State of Parana. The animals were identified and slaughtered in a slaughterhouse in the metropolitan region of Curitiba/PR- Brazil. From the animals that presented cysts during the post-mortem inspection, blood samples were also collected and submitted to the ELISA test for antibodies against $C$. bovis. The sensitivity coefficient in the ELISA test was $83.6 \%$, and the specificity coefficient was $92.8 \%$. Therefore, the ELISA test proved to be more sensitive than the post-mortem examination, because the latter failed to detect 06 carcasses with mild infection with cysticercosis (PPV 99.7\% - ELISA).
\end{abstract}

Key words: cysticercosis; immunodiagnosis; inspection; traceability 


\section{INTRODUÇÃO}

A ação preventiva do complexo teniase/cisticercose baseia-se em um conjunto de medidas que visa impedir a infecção do homem pela Taenia saginata e, com isto, bloquear o ciclo desses parasitas na natureza. A ocorrência desta parasitose vem sendo observada ao longo dos anos, com taxas de prevalência, que variam entre estados do Brasil (Ungar e Germano, 1992; Reis et al., 1996; Carmo et al.,1997; Souza et al., 2007a). Atualmente 0 recurso de maior expressão no controle deste complexo é a inspeção de carnes, com exame pósmorte criterioso, e o julgamento e saneamento adequado das carcaças parasitadas. No Brasil o Serviço de Inspeção Federal (SIF) fiscaliza em torno de $49 \%$ da carne consumida pela população. Todavia, na inspeção de rotina podem não ser detectados de 25 a $50 \%$ dos animais afetados, particularmente nos casos de infecção leve (Greets et al., 1980; Cabaret et al., 2002; Minozzo et al., 2004). Se levarmos em consideração a probabilidade de detecção, de acordo com o número de cistos $(4 \%$ de probabilidade para um cisto), o método "corta e olha" não é hábil para detectar todos os animais parasitados, e a maioria dos cistos continua na musculatura, servindo de fonte de infecção para humanos. Mesmo que fosse possível o exame de todas as massas musculares exploráveis, nas condições normais do procedimento de inspeção de carnes, não seria possível assegurar-se, em caso de resultado negativo, que a carcaça esteja livre de cistos. Como a inspeção é feita nos locais considerados de predileção do cisticerco, existe dificuldade no diagnóstico macroscópico, tornando-se necessário outros exames auxiliares que possam abranger todo o animal.
No diagnóstico de cisticercose animal "in vivo" encontra-se uma série de dificuldades como, por exemplo, o fato da maioria das infecções serem com baixo número de parasitos. Assim, outros métodos vêm sendo avaliados como, por exemplo, as técnicas "in vitro". Estes são representados por provas sorológicas como: fixação de complemento, hemaglutinação indireta, teste imunoenzimático (Enzyme-linkedimmunosorbent-assay - ELISA) entre outras. De forma geral, todas as provas apresentam falhas, sobretudo na detecção de infecções monocisticercótica (Ungar et al., 2001; Souza et al., 2007). Tentando minimizar as falhas no diagnóstico, muitos autores (Mann e Mann, 1947; Ginsberg, 1960; Fewster, 1967; Santos, 1976; Santos, 1993; Fukuda et al., 1998; Santos, 2002; Minozzo et al., 2004), demonstraram a preocupação de testar, empregar e até mesmo sugerir a padronização de técnicas que aumentem a chance de detecção da cisticercose no exame post mortem, bem como de definir a maior distribuição dos cisticercos no corpo do animal. Todavia, a maioria dos trabalhos avaliam infecções experimentais. Visando determinar a sensibilidade e especificidade do teste ELISA foi realizado o presente trabalho onde um estudo comparativo foi realizado entre os dados dos cisticercos encontrados na inspeção post mortem com os dados obtidos pela prova imunoenzimática.

\section{MATERIAL E MÉTODOS}

Foram examinados 26.633 animais procedentes de 139 municípios. Os animais eram na maioria bovinos azebuados, machos e fêmeas, na faixa etária de 18 a 60 meses. Os animais foram devidamente identificados e abatidos no frigorífico Argus Ltda, SIF 1710, localizado no município de São 
José dos Pinhais, Região Metropolitana de Curitiba - PR, no período entre julho a dezembro de 2000.

Os animais foram abatidos conforme tecnologia de produção padrão para bovinos. Os trabalhos de inspeção nas linhas foram desenvolvidos por uma equipe composta de sete agentes de inspeção devidamente treinados para desenvolver os trabalhos de inspeção post mortem, sob supervisão e responsabilidade de um Médico Veterinário do Serviço de Inspeção Federal (SIF). Os exames de rotina para pesquisa dos cisticercos nas linhas de inspeção dos diferentes órgãos (cabeça, língua, coração, diafragma e esôfago), foram realizados de acordo com as normas do SIF (Serviço de Inspeção Federal). De acordo com o artigo 176 do Regulamento de Inspeção Industrial e Sanitária de Produtos de Origem Animal (RIISPOA), caso fossem encontrados cisticercos nas linhas de inspeção, as lesões eram identificadas e as meiascarcaças, juntamente com as vísceras e cabeça, eram encaminhadas para o D.I.F. (Departamento de Inspeção Final) onde eram examinadas pelo veterinário, conforme procedimentos regulamentares. Os dados eram anotados em papeleta específica do D.I.F. e então, procedia-se a coleta dos cistos. Estes eram acondicionados em sacos plásticos devidamente identificados com uma etiqueta adesiva, na qual constava o número do lote, número do bovino e data do abate. Simultaneamente era preenchida uma ficha com os dados individuais de cada animal, conforme observações realizadas. Constavam os itens: data de abate, número de animais do lote, quantidade total de animais abatidos no dia, classificação dos cistos (vivos, caseosos e calcificados), localização anatômica e número de cistos, idade e sexo do animal. Juntamente à colheita dos cisticercos era colhido também o sangue do animal, da artéria braquial e acondicionado em tubos de ensaio descartáveis, sem anticoagulante e identificado com a data de abate, número do animal e do lote. O sangue e os cisticercos foram enviados ao laboratório, sob refrigeração. $O$ sangue foi submetido à centrifugação por 5 minutos a $5.000 \times \mathrm{g}$ para obtenção do soro. Em seguida o soro obtido foi pipetado e acondicionado em tubos plásticos de $2 \mathrm{~mL}$ com tampa, identificados por data, número do animal, número do lote e imediatamente submetidos ao congelamento em freezer comercial à temperatura média de $-8{ }^{\circ} \mathrm{C}$ até a sua utilização na prova do ELISA.

Quando na inspeção post mortem não foram observados cistos, o animal foi considerado negativo para cisticercos. Como controle negativo foi colhido sangue de 108 desses animais, dos quais 28 amostras foram usadas para determinar a sensibilidade do teste (Valor Preditivo Positivo) e 80 amostras para testar a capacidade de detecção de animais não infectados (Valor Preditivo Negativo) pelo teste ELISA.

Os cistos foram classificados como vivos (imaturos e maduros) e degenerados (Caseosos e Calcificados). Para a identificação dos cisticercos efetuou-se o processo de desinvaginação dos escolex que estavam vivos, os quais foram processados individualmente e identificados. Em seguida foi feita a fixação dos cisticercos em formol acético, para serem então corados pelo método do Carmim Clorídrico.

As lâminas foram lidas em microscópio óptico (100 e 400x), visualizando-se o protoescólex, colo e pseudo-estróbilo, diferenciando-se o $C$. bovis de $C$. celullosae pela ausência da dupla coroa de ganchos. O escólex pode ser observado quando comprimido entre duas lâminas observando suas características, independente do preparo histológico. 
Para o teste ELISA visando a pesquisa de anticorpos contraCysticercus bovis, foi usada metodologia padronizada por Minozzo et al. (2004). Foi realizada a reação em bloco utilizando-se seis concentrações de antígeno $(0,5 \mu \mathrm{g} / \mathrm{ml} ; 1,0 \mu \mathrm{g} / \mathrm{ml} ; 1,5$ $\mu \mathrm{g} / \mathrm{ml} ; 2,0 \mu \mathrm{g} / \mathrm{ml} ; 3,0 \mu \mathrm{g} / \mathrm{ml}$ e $4,0 \mu \mathrm{g} / \mathrm{ml}$ ) frente a 11 diluições de soro $(1 / 1,1 / 2$, $1 / 4,1 / 8,1 / 16,1 / 32,1 / 64,1 / 128,1 / 256$, $1 / 512$ e 1/1024). Foram utilizadas também amostras controles: positivo, negativo e branco. Como controles positivos foram usados soros de animais submetidos a infecções experimentais (Minozzo et al. 2004) e como controle negativo foram usados soros de animais com resultado de inspeção negativo e submetido ao teste de imunofluorescência e ELISA e que ambos se mostrassem negativos.

Para estabelecer o ponto de corte da reação entre soro reagente e não reagente foram usados 28 animais do grupo controles negativos, utilizando-se a média aritmética dos valores de absorbância, acrescentando-se ao valor, três desvios padrão da média utilizando a seguinte fórmula (Spiegel,1976).

$$
s=\sqrt{\sum_{n}^{[(\omega 2-\varpi) 2]}}
$$

Onde:

$\Sigma$ = somatória; $\varpi 2$ = absorbância de cada animal; $\bar{w}=$ média das absorbâncias; $\mathrm{N}$ = número de amostras.

\section{RESULTADOS}

\section{Padronização do ELISA}

Os resultados das absorbâncias para determinação do ponto de corte do teste ELISA (cut off) estão apresentados na Figura 1, sendo que para a padronização adotada para o teste imunoenzimático para as demais etapas foi: concentração de antígeno: $1 \mu \mathrm{g} /$ orifício; diluição do soro: 1:200; diluição do conjugado; 1:5.500; ponto de corte: absorbância de 0,295.

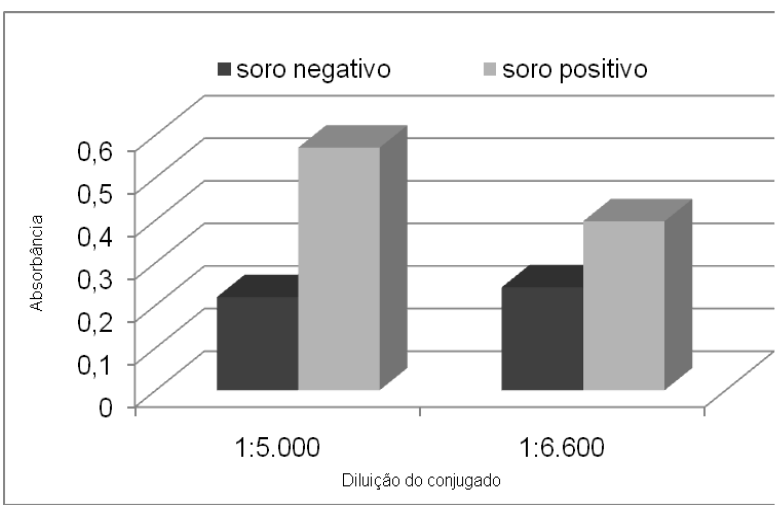

Figura 1 - Padronização do teste ELISA em soros bovinos para cisticercose. No exame pósmorte titulação do conjugado anti-lgG bovino com diluições 1:5.500 e 1:6.600.

Os exames sorológicos das carcaças indicaram que dos 812 animais que foram parasitologicamente comprovados para presença de cisticercos 679 foram positivos quando submetidos ao teste imunoenzimáticos utilizando-se 0 antígeno heterólogo Cysticercus longicollis. Os indicadores de sensibilidade, especificidade, valores preditivos e índices de Youden, de concordância e de discordância dos testes realizados são apresentados na Tabela 1.

Entre as 812 amostras analisadas pelo método ELISA, utilizando antígeno de C. longicollis, 133 (16,4\%) não reagiram, caracterizando falsos negativos. $O$ coeficiente de sensibilidade para a prova de enzimoimunoensaio (ELISA) foi de $83,6 \%$ e a especificidade de $92,8 \%$, quando examinados a totalidade dos soros positivos, parasitologicamente.

Quando se analisou os animais positivos segundo o estádio evolutivo do cisticerco observou-se, para o teste imunoenzimático, uma sensibilidade de $81,6 \%$ para cistos vivos, $84,1 \%$ para cistos caseosos e de $85,1 \%$ para cistos calcificados (Tabelas 2 e 3 ). 
Tabela 1 - Frequência e percentual de animais testados pelo método imunoenzimático (ELISA), com antígeno de Cysticercus longicollis

\begin{tabular}{cccc}
\hline Resultados & Grupo de estudo $(+)$ & \multicolumn{3}{c}{ Grupo controle (-) } \\
\hline Reagente & $679(83,62 \%)$ & 2 & $(7,14 \%)$ \\
Não reagente & $133(16,37 \%)$ & 26 & $(92,85 \%)$ \\
\hline Total (amostras) & $812(100,00 \%)$ & 28 & $(100,00 \%)$ \\
\hline
\end{tabular}

Tabela 2 - Animais soro reagentes e não reagentes, do grupo de estudo no teste de ELISA, utilizando antígeno Cysticercus longicollis

\begin{tabular}{ccccccc}
\hline Resultado & \multicolumn{2}{c}{ Cistos vivos } & \multicolumn{2}{c}{ Cistos caseosos } & \multicolumn{2}{c}{ Cistos calcificados } \\
\hline Reagentes & № & $\%$ & № & $\%$ & № & $\%$ \\
Não reagentes & 227 & 81,65 & 308 & 84,15 & 143 & 85,11 \\
Total & 51 & 18,34 & 58 & 15,84 & 25 & 14,88 \\
\hline & 278 & 100 & 366 & 100 & 168 & 100 \\
\hline
\end{tabular}

Tabela 3 - Sensibilidade, especificidade, valores preditivos positivo e negativo, índice de Youden, concordância e discordância dos testes de imunoenzimático aplicados a amostra de soro bovino de animais com cistos vivos, caseosos, calcificados e total (ELISA cl, \%)

\begin{tabular}{ccccc}
\hline Indicadores & C. vivos & C.caseosos & C.calcificados & Total \\
\hline Sensibilidade & 81,65 & 84,15 & 85,11 & 83,62 \\
Especificidade & 92,85 & 92,85 & 92,85 & 92,85 \\
Valor preditivo $(+)$ & 99,12 & 99,35 & 98,62 & 99,70 \\
Valor preditivo $(-)$ & 33,76 & 30,95 & 50,98 & 16,35 \\
Índice de Youden & 0,73 & 0,76 & 0,77 & 0,75 \\
\% De concordância & 81,65 & 84,15 & 85,11 & 83,62 \\
\% De discordância & 18,35 & 15,85 & 14,89 & 16,38 \\
\hline
\end{tabular}

Para testar a técnica de pesquisa de anticorpos por ELISA foram colhidos em linha de abate do SIF 1710, 80 amostras de soro de bovinos, os quais em inspeção pós-morte foram considerados não portadores de cisticercos. Dentre os 80 soros examinados, seis $(7,5 \%)$ apresentaram valores de absorbância acima do "cutoff", o que poderia indicar a presença de cisticercos (Tabela 4). Procedendo-se uma análise estatística de correlação entre os resultados do exame parasitológico para cisticercose no exame pós-morte dos animais abatidos no SIF 1710 e os resultados dos exames de enzimoimunoensaio do soro dos mesmos animais, obteve-se um coeficiente de correlação, $R=0,9978$, o que indica que houve uma forte correlação positiva.

Quando se avaliou estatísticamente os resultados da inspeção no que se refere à classificação dos cisticercos encontrados verificou-se que existe $99 \%$ de probabilidade de afirmar que 0 cisticerco na forma caseosa é o predominante no presente estudo (Tabela 5). O resultado também foi significativo a $1 \%$. Portanto, há $99 \%$ de probabilidade de afirmar que os cisticercos inviáveis são predominantes no exame parasitológico realizado no presente estudo.

\section{DISCUSSÃO}

Neste trabalho testou-se a técnica ELISA indireta para detecção de cisticercose, em animais confirmados parasitologicamente em inspeção pósmorte de carcaças. Trabalhou-se com antígeno extrato salino parcial de $C$. longicollis, um antígeno heterólogo produzido pelo CPPI (Centro de Produção e Pesquisa de Imunobioló- 
Tabela 4 - Animais reagentes e não reagentes, dos grupos de estudo e do grupo controle negativo, ao teste de ELISA, utilizando Cysticercus longicollis

\begin{tabular}{ccccc}
\hline Resultado & \multicolumn{2}{c}{ Grupo de estudo } & \multicolumn{2}{c}{ Grupo controle } \\
& № & \% & 6 & $\%$ \\
\hline Reagentes & 679 & 83,62 & 74 & 92,5 \\
Não reagentes & 133 & 16,37 & 74 & 100 \\
\hline Total & 812 & 100 & 80 &
\end{tabular}

Tabela 5 - Análise do Qui-Quadrado para os resultados da classificação parasitológica dos cisticercos vivos, caseosos e calcificados encontrados nos animais abatidos no SIF1710, no período de julho a dezembro de 2000

\begin{tabular}{cccc}
\hline Cisticercos & Vivos & Caseosos $^{*}$ & Calcificados \\
\hline Positivos & 293 & $394^{\mathrm{a}}$ & 210 \\
Controle & 299 & $299^{\mathrm{b}}$ & 299 \\
\hline
\end{tabular}

${ }^{*} \mathrm{P}<0,01$

gicas) da Secretaria de Estado da Saúde do Paraná. O teste de imunoensaio havia sido padronizado anteriormente por Minozzo et al. (2004) usando antígenos de $C$. longicollis e $C$. bovis em infecção experimental comprovando 85 e $91 \%$ de sensibilidade e 80 e $100 \%$ de especificidade. Como o ag- $C$. longicollis apresentou bons resultados foram avaliados animais naturalmente infectados (823 animais positivos comprovados pela técnica padrão ouro) e obteve-se $83,6 \%$ de sensibilidade, $92,8 \%$ de especificidade e concordância de $83,6 \%$. Quando os soros foram testados de acordo com a classificação imunológica dos cistos, encontrou-se uma sensibilidade de $81,6 \%$ para os cistos vivos, $84,1 \%$ para os caseosos e $85,1 \%$ para os calcificados, configurando-os verdadeiros positivos; e de não reagentes ou falsos-negativos respectivamente $18,3 \%, 15,8 \%$ e $14,9 \%$.

A prova ELISA segundo Bailly et al. (1988) tem alta sensibilidade variando de $75 \%$ a $90 \%$. Portanto, os dados obtidos (81,6 a $85,1 \%)$ estão dentro do esperado. Os resultados do teste ELISA em nosso estudo foram quantitativos, pois existia a correlação entre os valores da absorbância (DO) e os aspectos clínicos parasitológicos comprovados com os cistos detectados na inspeção post-morten.
Abuje et al. (1996) utilizando AgElisa com anticorpo monoclonal em um levantamento soroepidemiológico de $C$. bovis, divulgaram que o Ag-Elisa foi em média duas vezes mais sensível para detecção de animais positivos para cisticercose do que a inspeção de carnes, corroborando nossos resultados. Os resultados das prevalências variaram de duas até treze vezes maiores para Ag-ELISA do que para a inspeção de carne.

Wanzala et al. (2007) ao avaliarem animais infectados natural e artificialmente por teste ELISA, levando em consideração apenas cistos vivos (confirmados por exames parasitológicos) obtiveram 80 e $60 \%$ de sensibilidade e 60 e 100 de especificidade respectivamente. No, entanto, Monteiro (2004) relata que o teste de ELISA apresenta deficiências no diagnóstico de animais destinados ao abate, em virtude de sua baixa sensibilidade (5 a 32\%) para diferentes antígenos, quando considerado soro de animais com infecção natural, e no caso de animais infectados experimentalmente esse valor se mostra mais elevado (75 a 90\%). E com uma sensibilidade variando de 81 a $100 \%$ para diferentes antígenos, confrontando valores com o presente trabalho, em que a sensibilidade encontrada foi de $83,62 \%$ e especificidade de $92,8 \%$. 
O fato de ser encontrado um limiar de positividade a partir de um cisticerco no presente estudo deve-se, provavelmente pelo teste de ELISA, ser realizado em bovinos infectados naturalmente e nos quais a intensidade da resposta imune pode ser diferente das infecções experimentais, quando o animal recebe grande número de ovos em uma só ingestão e em um único período.

Estudo relativo à purificação antigênica predominantemente do interior do fluido vesicular de $T$. crassiceps, através da técnica de cromatografia de filtração molecular em Sephacryl S-300, revelou compartilhar identidade com a principal proteína vesicular do estado larval de $T$. saginata. A comparação do fluído vesicular deste último, traduz ao antígeno referido, melhor reagente para discriminar animais infectados e sadios (Kunz et al., 1989).

Dorny et al. (2000), usando AgElisa para determinar a prevalência da cisticercose bovina em gado de corte da Bélgica, usaram a técnica de préaquecer o soro a $100^{\circ} \mathrm{C}$ durante 15 minutos para dissociar o complexo imunológico e aumentar a especificidade e sensibilidade do teste ELISA, com menores resultados falso-positivos.

Resultados de estudos de Dorny et al. (2000), em uma pesquisa de soroprevalência de $C$. bovis em gado de corte na Bélgica confirmaram que apesar do tempo e esforço dispendidos pelos inspetores, o método de inspeção é extremamente falho e que a prevalência da cisticercose bovina utilizando ELISA (Ag-Elisa) foi de 10 vezes mais elevada que a inspeção clássica de carne.

O grupo testemunha, composto de 80 bovinos liberados para o consumo na inspeção pós-morte e considerados parasitologicamente negativos para cisticercose bovina, apresentou na prova de ELISA uma positividade de
$7,5 \%$. Os seis animais com D.O. acima do cutt-off podem ter colocado em risco a saúde do consumidor.

A cisticercose talvez possa passar despercebida facilmente porque os cisticercos podem não ser detectados nos cortes de coração e dos músculos masseteres. Em vários estudos foi mostrado que, através do fatiamento completo dos sítios de predileção, a média de prevalência aumenta de cinco a cinquenta vezes mais que a inspeção de rotina (Geerts et al., 1980; Minozzo et al., 2002; 2004). Porém, esta metodologia leva a depreciação comercial dos cortes.

$\mathrm{Na}$ Europa e Estados Unidos da América, as infecções de cisticercose são generalizadas (pluricisticercósicas), albergando de 30 a mais cisticercos, devido ao sistema e características de manejo do rebanho (confinamento), tipos de terreno, topografia e utilização do lodo de esgoto para fertilização das pastagens. No Brasil, as características de criação bovina são bem diversificadas, com sistema extensivo em grandes áreas de pastagem e menor contato com o homem e resíduos de poluição sanitária de esgotos, o que justifica as infecções no rebanho nacional caracterizarem-se como monocisticercósicas ou infecções leves (Souza et al., 2007).

Teste sorológico em bovinos nascidos e criados na mesma propriedade e com sorologia positiva sugerem a presença de indivíduos portadores de teníase, entre aqueles que têm contato com os animais da propriedade, ou ainda que a propriedade é banhada por rios que recebam esgoto sem prévio tratamento. Assim, através da avaliação sorológica para cisticercose bovina, pode-se monitorar a prevalência da teníase humana. Repetidos exames do rebanho podem indicar o período de introdução da zoonose na propriedade. Na compra de animais para engorda e posterior 
abate, a sorologia poderia ser um alerta de possíveis perdas futuras e ainda poderia ser usado para rastreabilidade dos animais.

\section{CONCLUSÃO}

O teste ELISA, padronizado com antígeno heterólogo, pode ser usado para diagnóstico da cisticercose bovina uma vez que apresenta alta sensibilidade e especificidade. A técnica aplicada em infecções naturais mostrouse mais sensível do que o exame postmortem, onde carcaças com contaminação leve por cisticercose podem não ser detectadas pela avaliação visual.

\section{REFERÊNCIAS}

ABUJE, J.A.O.; JOSEPH, M.; NGINYI, J.M. et al. Soroepidemiological survey of Taenia saginata cysticercosis in Kenya. Veterinary

Parasitology, v.64, n.3, p.177-185, 1996.

BAILLY, G.G.; MASON, P.R.; TRIJSSENAR, F.E.J. et al. Serological diagnosis of neurocysticercosis: evaluation of ELISA tests using fluid and other components of Taenia solium cysticerci as antigens. Transaction of Royal Society of Tropical Medicine and Hygiene, v.82: n.2, p.295-299, 1988.

CABARET, J.; GEERTS, S.; MADELINE, M.; BALLANDONNE, C.; BARBIER, D. The use of urban sewage sludge on pastures: the cysticercosis threat. Veterinary Research, v. 33, n.5, p. 575-597, 2002.

CARMO, R.G. Prevalência de cisticercose bovina no estado de Mato Grosso do Sul. Higiene Alimentar, v.11, p.45-50, 1997.

DORNY, P.; VERCAMMEN, F.; BRANDT, J. et al. Sero-epidemiological study of Taenia saginata cysticercosis in Belgian cattle.

Veterinary Parasitology, v.88, n.1, p.43-49, 2000.

FEWSTER, G.E. The incidence of Cysticercus bovis in cattle in Victoria and Tasmania.

Australian Veterinary Journal, v.43, p.450454, 1967.

FUKUDA, R.T.; SANTOS, I.F.; ANDRADE, C.R. Estudo comparativo entre técnicas de inspeção do diafragma para o diagnóstico da cisticercose bovina. Higiene Alimentar, v.12, n.55, p.51-62, 1998.

GEERTS, S.; KUMAR, V.; VAN DEN, A. Taenia saginata cysticercosis in slaughter cattle in Belgium. Diergeneeskd. Tijdschr. v.49, p.365374, 1980.

GINSBERG, A. The detection of Cysticercus bovis in the abattoir. Veterinary Record, v.72, n.16, p.310, 1960.

GREETS, S.; KUMAR, V.; ABBELLE, V.D. Taenia saginata cysticercosis in slaugter cattle in Belgium, Diergeneesk Tijsdchr, v.49, n.2, p.365-374, 1980.

HAYUNG, E.G.; SUMMER, M.P.; RHOADS, M.L. Development of a serologic assay for cysticercosis, using an antigen isolated from Taenia spp cyst fluid. American Journal of Veterinary Research, v.52, n.3, p.462-470, 1991.

KYVSGAARD, N.C.; ILSØE, B.; WILLEBERG, P. et al. A case-control study of risk factors in light Taenia saginata cysticercosis in Danish cattle. Acta Veterinaria Scandinavica, v.32, n.2, p. 243-252, 1991.

KUNZ, J.; KALLINA, B.; WATSCHKE, V. et al. Taenia crassiceps metacestode vesicular fluid antigens shared with Taenia solium larval stage and reactive with serum antibodies from patients with neurocysticercosis. Zentbl Bakteriol. v.271, p.510-520, 1989.

LUKES, S. Sorological methods in the diagnosis of $C$. bovis in cattle. In Internacional Symposium on Taeniasis/ Cysticercosis and Equinococcosis/ Hydatidosis, 1985. Ceske Budejovice, v.2, p.56-66.

MANN, I.; MANN, E. The distribuition of measles (Cysticercus bovis) in African bovine carcasses. Veterinary Journal, v.105, p.239-251, 1947.

MINOZZO, J.C. Prova de ELISA (enzymelinked immunosorbent assay) para diagnóstico de cisticercose bovina. Curitiba, 1997. 120p. Tese de mestrado, Curso de Medicina Veterinária, Universidade Federal do Paraná, 1997.

MINOZZO, J.; GUSSO, R.L..; CASTRO, E.C. et al. Experimental bovine infection with Taenia saginata eggs: recovery rate and cysticerci localization. Brazilian Archives of Biology and Technology, v.45, n.4, p.451-455, 2002.

MINOZZO, J.C.; THOMAZ-SOCCOL, V.; OLORTEGUI, C.C. et al. Teste Imunoenzimático (Enzyme-Linked Immunosorbent Assay) para diagnóstico da cisticercose bovina e estudo da cinética de produção de anticorpos contra- 
Cysticercus bovis. Ciência Rural, v.34, n.3, p.857-864, 2004.

MONTEIRO, M.L. Emprego de antígenos de larvas de Taenia crassiceps e Taenia solium em teste ELISA para diagnóstico da cisticercose bovina. Viçosa, 2004. $92 f$. Dissertação (Mestrado em Medicina Veterinária) - Universidade Federal de Viçosa, Minas Gerais- Viçosa, 2004.

REIS, D.O.; MUNDIM, M.J.S.; CABRAL, D.D. et al. Cisticercose bovina: 15 anos de ocorrência em animais abatidos em Uberlândia, Minas Gerais, Brasil. Higiene Alimentar, v.10, p.3335, 1996.

\section{SANTOS, I. F. Nova técnica de exame do} coração na rotina de inspeção da cisticercose bovina. Niterói, 1976. 48 f. Dissertação (Mestrado em Medicina Veterinária) - Faculdade de Veterinária, Universidade Federal Fluminense, 1976.

SANTOS, R. E. V. Exame post mortem pela técnica de Santos, no estudo da prevalência da cisticercose bovina em matadouros do Estado do Rio de Janeiro, comparada à utilizada pelo serviço de inspeção estadual. Niterói, 2002. Dissertação (Mestrado em Medicina Veterinária) - Faculdade de Veterinária, Universidade Federal Fluminense, Niterói, 2002.

SOUZA, R.M. et al. A importância do serviço de inspeção federal na vigilância sanitária de alimentos: Cisticercose bovina. Higiene Alimentar, v.11, p.19-21, 1997.
SOUZA V.K.; SILVA M.C.P.; KOWALCZUCK M. et al. Regiões anatômicas de maior ocorrência de Cysticercus bovis em bovinos submetidos à Inspeção Federal em Matadouro/Frigorífico no município de São José dos Pinhais, Paraná, de julho a dezembro de 2000. Revista Brasileira de Parasitologia Veterinária. v.16, n.2, p. 9296, 2007a.

SOUZA, V.K.; SILVA, M.C.P.; MINOZZO, J.C. et al. Prevalência de cisticercose bovina no estado do Paraná, sul do Brasil: avaliação de 26.465 bovinos inspecionados mo SIF 1710. Semina: Ciências Agrárias, v.28, n.4, p.675-684, 2007b.

SPIEGEL, M. R. Estatística. São Paulo: McGraw-Hill, 1976. 357 p.

UNGAR, M.L.; GERMANO, P.M.L. Prevalência da cisticercose bovina no Estado de São Paulo (Brasil). Revista Saúde Pública, São Paulo, v.26, p.167-172, 1992.

UNGAR, M.L.; GERMANO, P.M.L..; GERMANO, M.I.S. Cisticercose bovina. In: GERMANO, P.M.L.; GERMANO, M.I.S. Higiene e vigilância sanitárias de alimentos. 2.ed. São Paulo: Varela, 2001p.335-343.

WANZALA W.; KYULE, N. M.; ZESSIN K. H.; ONYANGO-ABUJE A. J.; KANG ETHE K. E.; OCHANDA H.; HARRISON. J. S. L. Evaluation of an antigen-ELISA in the diagnosis of bovine cysticercosis in Kenyan cattle Parasitology Research, v.100, n.3, p.539-548. 2007. 